\title{
Risk factors for early postoperative complications after bariatric surgery
}

\author{
Farah Husain', In Ho Jeong ${ }^{1,2}$, Donn Spight', Bruce Wolfe', Samer G Mattar ${ }^{1}$ \\ ${ }^{1}$ Department of Surgery, Oregon Health and Science University, Portland, OR, USA \\ ${ }^{2}$ Department of Surgery, Jeju National University School of Medicine, Jeju, Korea
}

\begin{abstract}
Purpose: Vertical sleeve gastrectomy (SG) and Roux-en-Y gastric bypass (RYGB) are currently the most common bariatric procedures. Although the safety of these operations has markedly improved, there continues to be a certain rate of complications. Such adverse events can have a significant deleterious effect on the outcome of these procedures and represent a costly burden on patients and society at large. A better understanding of these complications and their predictive factors may help ameliorate and optimize outcomes.

Methods: Seven hundred seventy-two consecutive patients who underwent SG or RYGB for morbid obesity between January 2011 and October 2015, in the Division of Bariatric Surgery at a tertiary institution, were included through retrospective review of the medical database. The complications were categorized and evaluated according to severity using the Clavien-Dindo classification system. Significant risk factors were evaluated by binary logistic regression to identify independent predictors and analyzed to identify their relationship with the type of complication.

Results: Independent predictors of severe complication after these procedures included male gender, open and revisional surgery, hypertension, and hypoalbuminemia. Hypoalbuminemia had significant associations with occurrence of deep surgical site infection and leak. Open surgery had significant associations with occurrence of superficial and deep surgical site infection and respiratory complications. Independent predictors of severe complication after laparoscopic primary RYGB included previous abdominal surgery. Previous abdominal surgery had significant associations with deep surgical site infection and leak.

Conclusion: Recognition and optimization of these risk factors would be valuable in operative risk prediction before bariatric surgery.

[Ann Surg Treat Res 2018;95(2):100-110]
\end{abstract}

Key Words: Bariatric surgery, Gastric bypass, Postoperative complications

\section{INTRODUCTION}

Although a great technical evolution in the field of bariatric surgery has led to the introduction of various surgical and endoscopic procedures, the 2 most popular bariatric procedures remain laparoscopic vertical sleeve gastrectomy (SG) and laparoscopic Roux-en-Y gastric bypass (RYGB) [1]. Because of a shortened operative time, the lack of anastomoses and the decreased extent of dissection, SG is usually regarded as a simpler and less invasive procedure than RYGB [1-3]. However, there has been ongoing debate concerning procedural superiority in terms of complication rates or mortality, as well as in terms the efficacy in weight loss and resolution of metabolic comorbidities [4-9].

There have been studies reporting on the preoperative risk factors of postoperative complications or mortalities after
Received August 28, 2017, Revised December 5, 2017,

Accepted December 12, 2017

Corresponding Author: In Ho Jeong

Department of Surgery, Oregon Health and Science University, 3181 SW

Sam Jackson Park Rd., Portland, OR 97239, USA

Tel: +1-503-494-1746, Fax: +1-503-418-4189

E-mail: jeong445@jejunu.ac.kr

ORCID code: https://orcid.org/0000-0002-0782-4542
Copyright (c) 2018, the Korean Surgical Society

(c) Annals of Surgical Treatment and Research is an Open Access Journal. All articles are distributed under the terms of the Creative Commons Attribution NonCommercial License (http://creativecommons.org/licenses/by-nc/4.0/) which permits unrestricted non-commercial use, distribution, and reproduction in any medium, provided the original work is properly cited. 
bariatric surgery. DeMaria et al. [10] published the Obesity Surgery Mortality Risk Score (OS-MRS). However, some later studies failed to replicate the OS-MRS and reported additional risk factors [11-16]. Therefore, we performed further analysis using more recent data in an effort to identify predictors of surgical complications with the goal of defining clinical predictors that could subsequently be used in risk reduction.

A grading system named the Clavien-Dindo classification, which can objectively describe surgical complications as five grades according to severity, regardless of operation type, was published in 2004 [17]. After the introduction of the ClavienDindo classification, only a few articles have reported the predictive factors of surgical complications or mortality after bariatric surgery and the distribution of Clavien-Dindo grade between RYGB and SG [18-20]. In this study, we performed further analysis according to the Clavien-Dindo classification to identify risk factors of severe early complications.

\section{METHODS}

\section{Patient selection and data collection}

From January 2011 to October 2015, a total of 772 patients diagnosed with morbid obesity meeting National Institutes of Health criteria for bariatric surgery underwent RYGB and SG, including all laparoscopic, open, primary, or revisional procedures. All consecutive patients with a minimal followup of 1 month were enrolled in this retrospective review. The adolescent patients, whose age at the time of the surgery was less than 18 years old, and the geriatric patients, more than 80 years old, were excluded from this study. Patients undergoing a gastric band or other types of bariatric surgery were likewise excluded from analysis.

Patients' medical records were reviewed retrospectively. Patient demographic characteristics were recorded along with clinical, surgical, and postoperative complication characteristics. Clinical findings were obtained, such as presence of preoperative morbidity, including cardiovascular, pulmonary, or endocrine disease, history of previous abdominal or chest surgery, smoking or other nicotine use, American Society of Anesthesiologists (ASA) physical status classification, age, sex, initial height and weight, laboratory findings such as albumin and hematocrit, and preoperative body mass index (BMI). Surgical findings, such as presence of open conversion, operative time, intraoperative blood loss, combined organ resection, type of operation, and prophylactic antibiotics usage were also included. Complication findings, such as reoperation, readmission, postoperative intensive care unit admission, 30day postoperative complication according to the Clavien-Dindo classification, surgical outcomes, and 30-day postoperative mortality were captured. This study was approved by the Institutional Review Board of the Oregon Health \& Science
University (OHSU, study 00016956). A waiver of informed consent was requested, and approval was obtained.

\section{Operative care and follow-up}

All patients had undergone preoperative evaluation, to include medical history, psychosocial history, physical examination, and laboratory testing to assess surgical risk. The preoperative assessment of all patients was multidisciplinary, to include the department of surgery, endocrinology, psychiatry, and anesthesiology. The patients underwent a rigorous dietary counseling education, medical optimization, and completion of the bariatric pathway at OHSU. Bariatric surgery was performed by five experienced bariatric surgeons at a single tertiary teaching institution. Using a standardized postoperative protocol, all patients were routinely managed. Postoperative care included prophylaxis for venous thromboembolism in all patients, including both low molecular weight heparin and sequential compression devices during the hospital stay. A clear liquid meal program was initiated with monitoring and counselling within 24 hours after any of the bariatric procedures. All patients were hospitalized for at least 24 hours and patients without complications were discharged any time thereafter. Postoperative contrast studies were not obtained routinely and drain placement was not routine. All patients were scheduled for follow-up 1 week after discharge. Use of Foley catheters varied between providers, but when used, was routinely discontinued on postoperative day 1 . Patients were required to ambulate on the day of surgery, ideally within 4 hours of arrival at the surgical ward.

\section{Statistical analysis}

The primary endpoint was early complication, which was defined as presence of any 30-day complications according to Clavien-Dindo classification [15]. These complications were categorized as moderate complications in Clavien-Dindo grades II or less, and Clavien-Dindo grades III, IV, and V were considered severe complications. The secondary endpoint was severe early complication of Clavien-Dindo grade III or more. Patients who experienced more than one complication were classified according to the highest grade of complications.

All statistical analyses were performed by using IBM SPSS ver. 18.0 (IBM Co., Armonk, NY, USA). Quantitative results are expressed as mean \pm standard deviation. Continuous variables, such as age, BMI, weight, and operative time were analyzed by using the Student t-test. The continuous variables such as BMI and age were converted into dichotomous variables. Categorical variables were analyzed by using the chi-square test or Fisher exact test. Binary logistical regression was used to detect the independent risk factors of surgical complications. All variables with $\mathrm{P}<0.25$ in the univariate analyses were included in the multivariate analysis. This multivariate regression model 
Table 1. Baseline demographic characteristics of the study cohort

\begin{tabular}{|c|c|c|c|c|}
\hline Characteristic & $\begin{array}{l}\text { Study cohort } \\
\qquad(\mathrm{n}=772)\end{array}$ & $\begin{array}{l}\text { Sleeve gastrectomy } \\
\qquad(\mathrm{n}=381)\end{array}$ & $\begin{array}{l}\text { Roux-en-Y gastric } \\
\text { bypass }(n=391)\end{array}$ & P-value \\
\hline Sex, female:male & 528:139 & 229:68 & 299:71 & 0.241 \\
\hline Age $(y r)$ & $47.9 \pm 12.1$ & $46.9 \pm 11.9$ & $48.7 \pm 12.2$ & 0.053 \\
\hline Preoperative weight $(\mathrm{kg})$ & $132.1 \pm 28.6$ & $132.1 \pm 28.9$ & $132.0 \pm 28.3$ & 0.932 \\
\hline Preoperative body mass index $\left(\mathrm{kg} / \mathrm{m}^{2}\right)$ & $46.6 \pm 8.4$ & $46.2 \pm 8.0$ & $47.0 \pm 8.7$ & 0.221 \\
\hline$<45$ & $375(48.6)$ & $198(51.9)$ & $177(45.3)$ & \\
\hline$\geq 45,<60$ & $346(44.8)$ & $161(42.3)$ & $185(47.3)$ & \\
\hline$\geq 60$ & $51(6.6)$ & $22(5.8)$ & $29(7.4)$ & \\
\hline ASA PS classification & & & & $0.007^{*}$ \\
\hline I (no disturbance) & $0(0)$ & $0(0)$ & $0(0)$ & \\
\hline II (mild disturbance) & $290(38.1)$ & $164(43.5)$ & $126(32.7)$ & \\
\hline III (severe disturbance) & $458(60.1)$ & $208(55.2)$ & $250(64.9)$ & \\
\hline IV (life threat) & $14(1.8)$ & $5(1.3)$ & $9(2.3)$ & \\
\hline \multicolumn{5}{|l|}{ Preoperative comorbidities } \\
\hline Diabetes & $341(44.2)$ & $155(40.7)$ & $186(47.6)$ & 0.054 \\
\hline Dyslipidemia & $334(43.3)$ & $140(36.7)$ & $194(49.6)$ & $<0.001^{*}$ \\
\hline Hypertension & $466(60.4)$ & $209(54.9)$ & $257(65.7)$ & $0.002 *$ \\
\hline Obstructive sleep apnea & $524(67.9)$ & $239(62.7)$ & $285(72.9)$ & $0.003^{*}$ \\
\hline Chronic obstructive lung disease & $32(4.1)$ & $11(2.9)$ & $21(5.4)$ & 0.083 \\
\hline Previous cardiac surgery & $13(1.7)$ & $5(1.3)$ & $8(2.0)$ & 0.428 \\
\hline Chronic corticosteroid use & $8(1.0)$ & $5(1.3)$ & $3(0.8)$ & 0.455 \\
\hline History of angina & $21(2.7)$ & $7(1.8)$ & $14(3.6)$ & 0.137 \\
\hline Previous abdominal surgery & $111(14.4)$ & $49(12.9)$ & $62(15.9)$ & 0.236 \\
\hline Abnormal albumin, $<3.0 \mathrm{~g} / \mathrm{dL}$ & $7(1.1)$ & $1(0.3)$ & $6(1.8)$ & 0.086 \\
\hline Abnormal hematocrit, $<32 \%$ & $17(2.4)$ & $7(2.0)$ & $10(2.7)$ & 0.581 \\
\hline Gastroesophageal reflux disease & $300(38.9)$ & $119(31.2)$ & $181(46.3)$ & $<0.001^{*}$ \\
\hline Deep vein thrombosis & $29(3.8)$ & $13(3.4)$ & $16(4.1)$ & 0.619 \\
\hline Pulmonary thromboembolism & $16(2.1)$ & $10(2.6)$ & $6(1.5)$ & 0.288 \\
\hline Venous stasis disease & $1(0.1)$ & 0 & $1(0.3)$ & 0.323 \\
\hline Chronic renal insufficiency & $4(0.5)$ & $2(0.5)$ & $2(0.5)$ & 0.979 \\
\hline Therapeutic anticoagulation & $30(3.9)$ & $18(4.7)$ & $12(3.1)$ & 0.234 \\
\hline Smoker within the last year & $85(11.0)$ & $34(8.9)$ & $51(13.0)$ & 0.068 \\
\hline Functional status & & & & 0.375 \\
\hline Partially dependent & $13(1.7)$ & $8(2.1)$ & $5(1.3)$ & \\
\hline Independent & $759(98.3)$ & $373(97.9)$ & $386(98.7)$ & \\
\hline Surgical approach & & & & 0.103 \\
\hline Laparoscopic & $732(94.8)$ & $367(96.3)$ & $365(93.4)$ & \\
\hline Conversion to open & $16(2.1)$ & $4(1.0)$ & $12(3.1)$ & \\
\hline Open & $24(3.1)$ & $10(2.6)$ & $14(3.6)$ & \\
\hline Surgical type & & & & 0.791 \\
\hline Primary operation & $745(96.5)$ & $367(96.3)$ & $378(96.7)$ & \\
\hline Revisional operation & $27(3.5)$ & $14(3.7)$ & $13(3.3)$ & \\
\hline No. of patients according to year of surgery & & & & $<0.001^{*}$ \\
\hline 2011 & 123 & 8 & 115 & \\
\hline 2012 & 133 & 23 & 110 & \\
\hline 2013 & 138 & 62 & 76 & \\
\hline 2014 & 183 & 129 & 54 & \\
\hline 2015 & 195 & 159 & 36 & \\
\hline
\end{tabular}

Values are presented as mean \pm standard deviation or number (\%). ASA PS, American Society of Anesthesiologists physical status. $* \mathrm{P}<0.05$, significant difference. 
examined dichotomous outcomes and their associated risk factors. The relationship between the number of comorbid risk factors and severe complication rate was assessed using Pearson correlation coefficient. $\mathrm{P}<0.05$ was considered to indicate statistical significance.

\section{RESULTS}

\section{Patient characteristics and surgical outcome}

During the study period, 381 and 391 patients with morbid obesity underwent SG and RYGB as weight loss procedures, respectively (Table 1). The number of SG continued to rise annually with gradual decline of RYGB since 2011 ( $P<0.001$ ). Distribution of age, sex, BMI, and surgical approach were similar with no statistically significant difference between SG group and RYGB group. The patients who underwent RYGB had significantly higher ASA physical status classification and higher incidence of comorbidities such as dyslipidemia, hypertension, obstructive sleep apnea and gastroesophageal reflux disease than patients who underwent SG.

Overall postoperative early complication rates were $8.2 \%$. Complications occurred in $5.5 \%$ and $10.7 \%$ patients following SG and RYGB, respectively ( $\mathrm{P}=0.008$ ) (Table 2). However, there was no significant difference in incidence of severe complications between the groups $(2.1 \%$ for SG vs, $2.3 \%$ for RYGB, P = 0.848) (Table 3). The most frequent type of complication was superficial wound infection in both groups (Table 3). There was no significant difference in 30-day mortality $(P=0.494)$.

\section{Risk factors of early complications after SG and RYGB}

To find the association between the independent variables, such as demographic, operative data, or comorbidity variables, and severe complications, univariate analysis was performed (Table 4).
The risk factors associated with severe complication were male sex, open bariatric surgery, revisional bariatric surgery, long operative time of $>120$ minutes in SG, smoker within the last year, ASA physical status classification $\geq$ III, and preoperative morbidities such as chronic obstructive pulmonary disease (COPD), pulmonary thromboembolism, hypertension, previous abdominal surgery, therapeutic anticoagulation, and abnormal serum albumin $<3.5 \mathrm{~g} / \mathrm{dL}$ (Table 4). When based on the number of these factors, there was a positive correlation between the number of comorbidities and severe complication rates (correlation efficient $=0.239, \mathrm{P}<0.001$ ).

As shown in Table 5, independent risk factors of severe complication after these procedures include male sex, open surgery, hypertension, and abnormal serum albumin $<3.5 \mathrm{~g} /$ dL.

\section{Type of complication according to risk factors after SG and RYGB}

The relationship between type of complication and specific risk factors that had statistical significance on multivariate analysis was assessed.

In order to assess the impact of serum albumin levels on the type of postoperative complication, serum albumin levels were categorized as 3 groups with reference value of 3.5 to $5.3 \mathrm{mg} /$ dL (Fig. 1). The serum albumin levels had statistical association with overall complication rate (odds ratio [OR], 3.22; $\mathrm{P}=$ 0.038) and severe complication rate $(P<0.001)$ (Table 4). Low preoperative serum albumin level had statistical association with the occurrence of deep surgical site infections $(\mathrm{P}<0.001)$ and leaks ( $P<0.001)$, but not for superficial surgical site infection $(P=0.732)$, respiratory complications $(P=0.427)$, and urinary tract infections $(\mathrm{P}=0.821)$. In addition, other significant risk factors, such as hypertension and male sex, had no statistical associations with the occurrence of any specific type of complication.

Table 2. Postoperative outcomes of the study cohort

\begin{tabular}{|c|c|c|c|c|}
\hline Characteristic & $\begin{array}{l}\text { Study cohort } \\
\quad(\mathrm{n}=772)\end{array}$ & $\begin{array}{l}\text { Sleeve gastrectomy } \\
\qquad(\mathrm{n}=381)\end{array}$ & $\begin{array}{l}\text { Roux-en-Y gastric } \\
\text { bypass }(n=391)\end{array}$ & P-value \\
\hline Operative time (min) & $141.9 \pm 73.0$ & $\begin{array}{c}87.4 \pm 40.7 \\
\text { (median, 80.0) }\end{array}$ & $\begin{array}{c}194.9 \pm 56.7 \\
\text { (median, 185.0) }\end{array}$ & $<0.001^{*}$ \\
\hline Laparoscopic & $139.0 \pm 71.9$ & $83.7 \pm 35.5$ & $194.7 \pm 54.2$ & \\
\hline Conversion to open & $220.4 \pm 84.4$ & $194.3 \pm 69.4$ & $229.2 \pm 89.8$ & \\
\hline Open & $176.4 \pm 63.6$ & $180.9 \pm 41.1$ & $173.2 \pm 77.2$ & \\
\hline Conversion to open surgery & $16(2.1)$ & $4(1.0)$ & $12(3.1)$ & 0.074 \\
\hline Return to operating room & $12(1.6)$ & $5(1.3)$ & $7(1.8)$ & 0.773 \\
\hline Length of hospital stay (day) & $2.4 \pm 4.4$ & $2.1 \pm 5.4$ & $2.7 \pm 3.2$ & $0.037 *$ \\
\hline Thirty-day mortality & $1(0.1)$ & $1(0.3)$ & $0(0)$ & 0.494 \\
\hline Total complications & $63(8.2)$ & $21(5.5)$ & $42(10.7)$ & $0.008^{*}$ \\
\hline
\end{tabular}

Values are presented as mean \pm standard deviation or number (\%).

$* P<0.05$, significant difference. 
Table 3. Postoperative 30-day complications distribution by Clavien-Dindo classification grade

\begin{tabular}{|c|c|c|c|c|}
\hline $\begin{array}{l}\text { Clavien-Dindo grade } \\
\text { and type of complication }\end{array}$ & $\begin{array}{l}\text { Study cohort } \\
\qquad(\mathrm{n}=772)\end{array}$ & $\begin{array}{l}\text { Sleeve } \\
\text { gastrectomy } \\
(\mathrm{n}=381)\end{array}$ & $\begin{array}{l}\text { Roux-en-Y gastric } \\
\text { bypass }(\mathrm{n}=391)\end{array}$ & P-value \\
\hline $\begin{array}{l}\text { I (Any deviation from the normal postoperative course } \\
\text { without the need for pharmacological treatment or } \\
\text { surgical, endoscopic, and radiological interventions; } \\
\text { allowed regimens as antiemetics, antipyretics, } \\
\text { analgetics, diuretics, electrolytes, and physiotherapy) }\end{array}$ & $7(9.1)$ & $2(0.5)$ & $5(1.3)$ & $0.046^{*}$ \\
\hline Acute hypoxia & 6 & 2 & 4 & \\
\hline Brachial plexus nerve injury & 1 & 0 & 1 & \\
\hline $\begin{array}{l}\text { Il (Requiring pharmacological treatment with drugs other } \\
\text { than such allowed for grade I complications; blood } \\
\text { transfusions and total parenteral nutrition are also included) }\end{array}$ & $39(5.1)$ & $11(2.9)$ & $28(7.2)$ & \\
\hline Superficial surgical site infection & 15 & 4 & 11 & \\
\hline Urinary tract infection & 14 & 4 & 10 & \\
\hline Pneumonia & 3 & 1 & 2 & \\
\hline Deep surgical site infection & 4 & 2 & 2 & \\
\hline Digestive bleeding with transfusion & 1 & 0 & 1 & \\
\hline Acute renal insufficiency & 1 & 0 & 1 & \\
\hline Seizure with hypercapnia & 1 & 0 & 1 & \\
\hline III (Requiring surgical, endoscopic or radiological intervention) & $14(1.8)$ & $5(1.3)$ & $9(2.3)$ & \\
\hline Gastric leak & 7 & 2 & 5 & \\
\hline Bowel obstruction & 1 & 1 & 0 & \\
\hline Intra-abdominal abscess & 4 & 1 & 3 & \\
\hline Wound disruption & 1 & 1 & 0 & \\
\hline Deep surgical site infection & 1 & 0 & 1 & \\
\hline $\begin{array}{l}\text { IV (Life-threatening complication requiring } \\
\text { intermediate care/intensive care unit management) }\end{array}$ & $2(0.3)$ & $2(0.5)$ & 0 & \\
\hline Pulmonary embolism & 1 & 1 & 0 & \\
\hline Acute respiratory failure & 1 & 1 & 0 & \\
\hline V (Death of a patient) & $1(0.1)$ & $1(0.3)$ & 0 & \\
\hline Death from hemorrhagic shock & 1 & 1 & 0 & \\
\hline Total complications & $63(8.2)$ & $21(5.5)$ & $42(10.7)$ & $0.008^{*}$ \\
\hline \multicolumn{5}{|l|}{ Total severe complications } \\
\hline Clavien-Dindo grade $\geq$ III & $17(2.2)$ & $8(2.1)$ & $9(2.3)$ & \\
\hline
\end{tabular}

Values are presented as number (\%) or number.

$* \mathrm{P}<0.05$, significant difference.

Open surgery had a statistical association with overall complication rate $(\mathrm{OR}, 5.13 ; \mathrm{P}=0.015)$ and severe complication rate $(\mathrm{P}=0.015)$ (Table 4$)$. When compared with the laparoscopic approach, open surgery had statistically significant associations with the occurrence of superficial surgical site infection $(\mathrm{P}<$ $0.001)$, deep surgical site infection $(\mathrm{P}=0.005)$, and respiratory complication $(\mathrm{P}=0.001)$, but not for urinary tract infection $(\mathrm{P}$ $=0.400)$ or leak $(\mathrm{P}=0.199)$ (Fig. 2).

\section{Type of complication according to risk factors after laparoscopic SG or RYGB}

In order to identify significant risk factors according to separate group based on surgical procedure or approach, the cases with laparoscopic primary SG or RYGB were analyzed.
Complications occurred in 3.5\% and 9.5\% patients following laparoscopic SG and laparoscopic RYGB, respectively ( $\mathrm{P}=$ 0.001) (Table 6). However, there was no significant difference of incidence of severe complication between the groups $(1.1 \%$ for SG vs. $1.1 \%$ for RYGB, $\mathrm{P}=0.752$ ).

The risk factors associated with severe complication after laparoscopic primary SG included male sex, preoperative BMI $\geq 60 \mathrm{~kg} / \mathrm{m}^{2}$, RYGB, smoker within the last year, deep vein thrombosis, therapeutic anticoagulation, and abnormal serum albumin $<3.5 \mathrm{~g} / \mathrm{dL}$ (Table 6). However, independent risk factors of severe complication after laparoscopic SG were not identified (Table 7). None of risk factors after laparoscopic SG had statistical associations with the occurrence of specific type of complication. 
Table 4. Risk factors for severe complication

\begin{tabular}{|c|c|c|c|c|c|}
\hline Variable & $\begin{array}{c}\text { No. of } \\
\text { patients (\%) }\end{array}$ & $\begin{array}{c}\text { No. of } \\
\text { complications }(\%)^{\mathrm{a})}\end{array}$ & $\begin{array}{l}\text { Odds } \\
\text { ratio }\end{array}$ & $\begin{array}{l}\text { 95\% Confidence } \\
\text { interval }\end{array}$ & P-value \\
\hline Age $\geq 50$ yr & $311(46.5)$ & $9(2.9)$ & 2.10 & $0.70-6.35$ & 0.189 \\
\hline Male sex & $139(20.8)$ & $7(5.0)$ & 3.95 & $1.36-11.45$ & $0.007^{*}$ \\
\hline Body mass index $\geq 60 \mathrm{~kg} / \mathrm{m}^{2}$ & $51(6.6)$ & $2(3.9)$ & 1.92 & $0.43-8.64$ & 0.311 \\
\hline Roux-en-Y gastric bypass procedure & $391(50.6)$ & $9(2.3)$ & 1.10 & $0.42-2.88$ & 0.848 \\
\hline Open bariatric surgery & $24(3.1)$ & $7(29.2)$ & 30.39 & $10.33-89.39$ & $<0.001 *$ \\
\hline Laparoscopic surgery with open conversion & $16(2.1)$ & $0(0)$ & 0.98 & $0.97-0.99$ & 0.544 \\
\hline Revisional bariatric surgery & $27(3.5)$ & $6(22.2)$ & 19.07 & $6.44-56.43$ & $<0.001^{*}$ \\
\hline \multicolumn{6}{|l|}{ Long operative time } \\
\hline$>120$ min in sleeve gastrectomy & $69(18.1)$ & $5(7.2)$ & 8.05 & $1.88-34.53$ & $0.006^{*}$ \\
\hline$>240$ min in Roux-en-Y gastric bypass & $63(16.1)$ & $0(0)$ & 0.97 & $0.96-0.99$ & 0.183 \\
\hline Smoker within the last year & $85(11.0)$ & $5(5.9)$ & 3.52 & $1.21-10.24$ & $0.031 *$ \\
\hline Functional status: partial dependence & $13(1.7)$ & $0(0)$ & 0.98 & $0.97-0.99$ & 0.585 \\
\hline ASA PS classification $\geq$ III & $472(61.9)$ & $15(3.2)$ & 4.73 & $1.07-20.82$ & $0.023 *$ \\
\hline Prophylactic antibiotics use & $341(44.2)$ & $6(1.8)$ & 1.39 & $0.38-5.12$ & 0.765 \\
\hline Diabetes & $16(2.1)$ & $2(12.5)$ & 0.68 & $0.25-1.87$ & 0.623 \\
\hline Chronic obstructive lung disease & $524(67.9)$ & $9(1.7)$ & 7.99 & $2.45-26.07$ & $0.004^{*}$ \\
\hline Pulmonary thromboembolism & $300(38.9)$ & $8(2.7)$ & 7.06 & $1.47-33.83$ & $0.046^{*}$ \\
\hline Obstructive sleep apnea & $21(2.7)$ & $1(4.8)$ & 0.52 & $0.20-1.38$ & 0.182 \\
\hline Gastroesophageal reflux disease & $334(43.3)$ & $15(1.5)$ & 1.41 & $0.54-3.69$ & 0.483 \\
\hline Myocardial ischemia & $466(60.4)$ & $15(3.2)$ & 2.30 & $0.29-18.19$ & 0.377 \\
\hline Hyperlipidemia & $29(3.8)$ & $2(6.9)$ & 0.54 & $0.19-1.55$ & 0.324 \\
\hline Hypertension & $4(0.5)$ & $0(0)$ & 5.06 & $1.15-22.27$ & $0.022 *$ \\
\hline Deep vein thrombosis & $8(1.0)$ & $0(0)$ & 3.60 & $0.78-1.51$ & 0.131 \\
\hline Renal insufficiency & $13(1.7)$ & $0(0)$ & 0.98 & $0.97-0.99$ & 0.763 \\
\hline Chronic steroid use & $111(14.4)$ & $9(8.1)$ & 0.98 & $0.97-0.99$ & $>0.999$ \\
\hline Previous cardiac surgery & $30(3.9)$ & $3(10.0)$ & 0.98 & $0.97-0.99$ & 0.585 \\
\hline Previous abdominal surgery & $89(14.3)$ & $8(9.0)$ & 7.20 & $2.72-19.09$ & $<0.001^{*}$ \\
\hline Therapeutic anticoagulation & $78(10.8)$ & $4(5.2)$ & 5.78 & $1.57-21.30$ & $0.025 *$ \\
\hline Abnormal serum albumin $<3.5 \mathrm{~g} / \mathrm{dL}$ & $341(44.2)$ & $6(1.8)$ & 7.45 & $2.63-21.10$ & $<0.001^{*}$ \\
\hline Anemia (abnormal hematocrit < 36\%) & $32(4.1)$ & $4(12.5)$ & 2.62 & $0.83-8.23$ & 0.102 \\
\hline
\end{tabular}

ASA PS, American Society of Anesthesiologists physical status.

${ }^{\mathrm{a})}$ The percentage of the patient with severe complication among the risk cohort. ${ }^{*} \mathrm{P}<0.05$, significant difference.

The risk factors associated with severe complication after laparoscopic primary RYGB included smoker within the last year, COPD, previous abdominal surgery, abnormal serum albumin $<3.5 \mathrm{~g} / \mathrm{dL}$, and anemia (Table 8). Independent risk factors of severe complication after laparoscopic RYGB included previous abdominal surgery (Table 9). Previous abdominal surgery had statistical association with the occurrence of deep surgical site infections $(P=0.001)$ and leaks $(P=0.017)$, but not for superficial surgical site infection $(P=0.372)$, respiratory complications $(\mathrm{P}=0.570)$, or urinary tract infections $(\mathrm{P}=0.162)$ (Fig. 3).

\section{DISCUSSION}

Bariatric surgery is currently considered the most efficient method of treatment for morbid obesity [1,2]. As is well known, bariatric surgery provides more durable weight loss and resolution of metabolic comorbidities, and these are 2 critical factors in support of surgical intervention $[18,19]$. With regard to procedural safety, outcome of these operations has markedly improved. A better understanding and optimization of risk factors may be helpful in predicting operative risk before bariatric surgery and dealing with the adverse event.

A risk stratification system evaluating possible postoperative complications after bariatric surgery was first proposed in 2007, along with five preoperative predicting factors; advanced age $\geq 45$ years, superobesity of BMI $\geq 50 \mathrm{~kg} / \mathrm{m}^{2}$, hypertension, male sex, and risk factors for pulmonary thromboembolism such as pulmonary hypertension, previous pulmonary thromboembolism, vena cava filter or hypoventilation of $\mathrm{PaCO}_{2}$ $\geq 45 \mathrm{mmHg}$ [10]. Thereafter, articles discussing factors which predict complications or mortality after bariatric surgery have been on the increase, but later studies have reported a variety of risk factors with no solid conclusion [11-14]. Furthermore, 
Table 5. Multivariate analysis by the binary logistic regression for severe complication

\begin{tabular}{lccc}
\hline \multicolumn{1}{c}{ Variable } & Odds ratio & 95\% Confidence interval & P-value \\
\hline Age & 0.67 & $0.11-4.15$ & 0.670 \\
Male sex & 20.51 & $1.70-247.43$ & $0.017^{*}$ \\
Open bariatric surgery & 48.58 & $2.14-1104.29$ & $0.015^{*}$ \\
Revisional bariatric surgery & 5.25 & $0.12-240.21$ & 0.395 \\
Long operative time $>$ 120 min in sleeve gastrectomy & 0.35 & $0.02-6.28$ & 0.478 \\
Smoker within the last year & 5.24 & $0.60-45.60$ & 0.133 \\
ASA PS classification $\geq$ III & 0.65 & $0.03-12.22$ & 0.772 \\
Chronic obstructive lung disease & 3.87 & $0.29-52.27$ & 0.309 \\
Pulmonary thromboembolism & 0.34 & $0.01-17.23$ & 0.592 \\
Obstructive sleep apnea & 0.19 & $0.02-1.50$ & 0.115 \\
Hypertension & 90.53 & $1.38-5,948.99$ & $0.035^{*}$ \\
Deep vein thrombosis & 0.91 & $0.02-42.93$ & 0.962 \\
Previous abdominal surgery & 6.72 & $0.63-71.76$ & 0.115 \\
Therapeutic anticoagulation & 9.47 & $0.40-224.95$ & 0.164 \\
Abnormal serum albumin $<3.5$ g/dL & 48.58 & $4.77-494.53$ & $0.001^{*}$ \\
Anemia (abnormal hematocrit $<36 \%)$ & 0.93 & $0.78-1.11$ & 0.424 \\
\hline
\end{tabular}

ASA PS, American Society of Anesthesiologists physical status. $* \mathrm{P}<0.05$, significant difference.

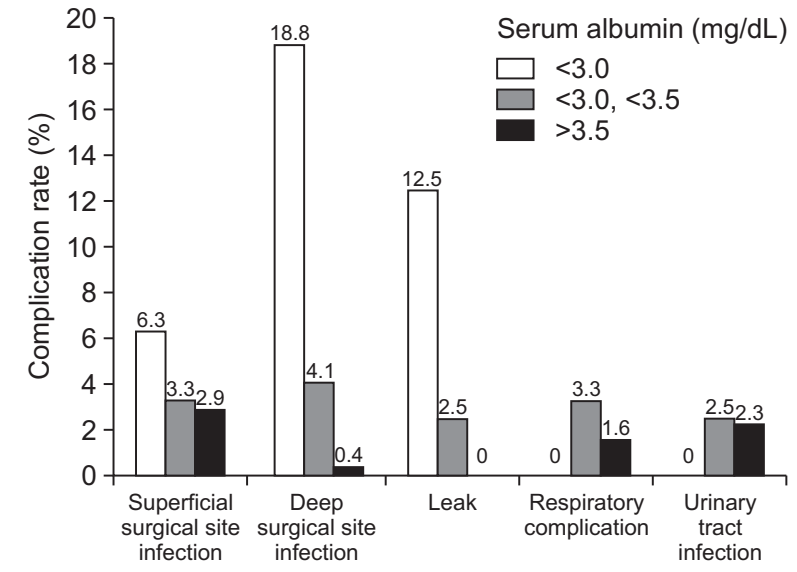

Fig. 1. Relationship between preoperative serum albumin level and type of complication.

a major contributor to confounding conclusions has been the variability in objectively quantifying postoperative complications $[8,13,16,18,21]$. Therefore, Clavien-Dindo classification was utilized for consistent and objective grading of postoperative complications in this study. Clavien grade III or more was referred to as severe complication according to presence of additional endoscopic or surgical intervention.

The statistically relevant risk factors predicting overall or severe complication included older age $[10,22,23]$, superobesity of BMI $[10,11,13,14,22]$, male sex $[10,13,23,24]$, ASA physical status classification [25], functional status of partial dependence [11,14,22,25], open approach [25-27], type of bariatric procedure $[14,21,25]$, smoking [28], early surgeon experience or hospital volume [11,24], operative time [27], prophylactic antibiotics usage

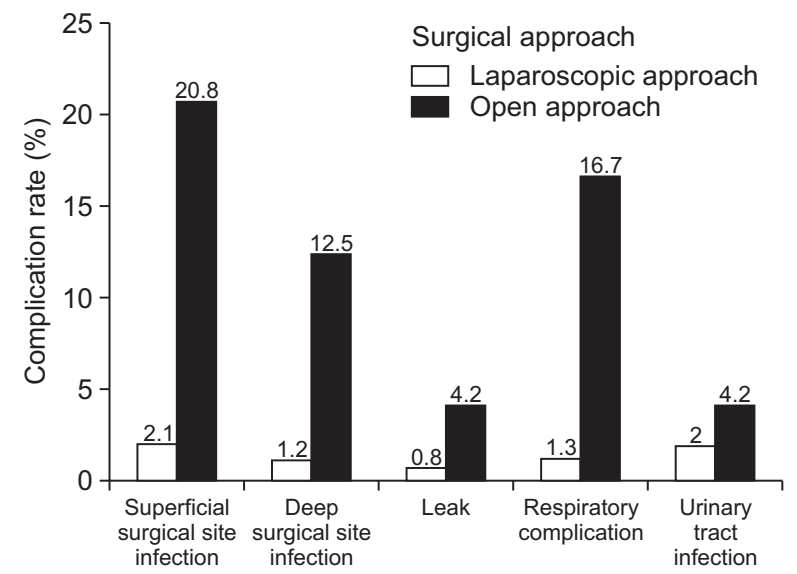

Fig. 2. The type of complication according to surgical approach.

[24], and comorbid disease such as COPD [23,28], dyslipidemia [21], hypertension $[10,14,23,25]$, diabetes [13,23], anemia [13,23], hypoalbuminemia [22], congestive heart failure [13], recent angina [14], depression [23], pulmonary thromboembolism $[10,11]$, obstructive sleep apnea [11], deep vein thrombosis [11], chronic steroid use [13], liver disease [13], bleeding disorder [14], and stroke [14]. Similarly, male gender, open surgery, revisional surgery, long operative time of $>120$ minutes in SG, smoker within last year, ASA physical status classification $\geq$ III, COPD, pulmonary thromboembolism, hypertension, previous abdominal surgery, therapeutic anticoagulation and abnormal serum albumin $<3.5 \mathrm{~g} / \mathrm{dL}$ were identified as risk factors associated with severe complication in our study.

There are few articles regarding type of complication 
Table 6. Risk factors for severe complication of laparoscopic sleeve gastrectomy

\begin{tabular}{|c|c|c|c|c|c|}
\hline Variable & $\begin{array}{c}\text { No. of } \\
\text { patients (\%) }\end{array}$ & $\begin{array}{c}\text { No. of } \\
\text { complications }(\%)^{\mathrm{a})}\end{array}$ & $\begin{array}{l}\text { Odds } \\
\text { ratio }\end{array}$ & $\begin{array}{c}\text { 95\% Confidence } \\
\text { interval }\end{array}$ & P-value \\
\hline Age $\geq 50 \mathrm{yr}$ & $126(44.1)$ & $2(1.6)$ & 0.79 & $0.11-5.65$ & $>0.999$ \\
\hline Male sex & $64(22.5)$ & $4(6.3)$ & 1.07 & $1.00-1.14$ & $0.002^{*}$ \\
\hline Body mass index $\geq 60 \mathrm{~kg} / \mathrm{m}^{2}$ & $21(5.7)$ & $2(9.5)$ & 1.10 & $0.96-1.26$ & $0.017^{*}$ \\
\hline Open conversion & $1(0.3)$ & $0(0)$ & 0.99 & $0.98-1.00$ & $>0.999$ \\
\hline Long operative time $>120 \mathrm{~min}$ & $57(15.5)$ & $1(1.8)$ & 0.55 & $0.06-5.34$ & 0.491 \\
\hline Smoker within the last year & $33(9.0)$ & $2(6.5)$ & 1.06 & $0.97-1.15$ & $0.042 *$ \\
\hline Functional status: partial dependence & $7(1.9)$ & $0(0)$ & 0.99 & $0.98-1.00$ & $>0.999$ \\
\hline ASA PS classification $\geq \mathrm{III}$ & $203(55.6)$ & $4(2.0)$ & 1.02 & $1.00-1.04$ & 0.132 \\
\hline Prophylactic antibiotics use & $170(46.7)$ & $1(0.6)$ & 2.65 & $0.27-25.76$ & 0.626 \\
\hline Diabetes & $150(40.8)$ & $3(2.0)$ & 1.02 & $0.99-1.04$ & 0.309 \\
\hline Chronic obstructive lung disease & $10(2.7)$ & $1(10.0)$ & 1.10 & $0.90-1.36$ & 0.105 \\
\hline Pulmonary thromboembolism & $9(2.4)$ & $1(11.1)$ & 1.12 & $0.89-1.41$ & 0.095 \\
\hline Obstructive sleep apnea & $231(62.8)$ & $3(1.3)$ & 1.01 & $0.99-1.03$ & $>0.999$ \\
\hline Gastroesophageal reflux disease & $115(31.3)$ & $1(0.9)$ & 1.00 & $0.98-1.02$ & $>0.999$ \\
\hline Myocardial ischemia & 7 (1.9) & $1(14.3)$ & 1.16 & $0.86-1.57$ & 0.074 \\
\hline Hyperlipidemia & $136(37.0)$ & $1(0.7)$ & 1.00 & $0.97-1.02$ & $>0.999$ \\
\hline Hypertension & 197(53.5) & $4(2.0)$ & 1.02 & $1.00-1.04$ & 0.127 \\
\hline Deep vein thrombosis & $12(3.3)$ & $2(16.7)$ & 1.19 & $0.93-1.54$ & $0.006^{*}$ \\
\hline Renal insufficiency & $2(0.5)$ & $0(0)$ & 0.99 & $0.98-1.00$ & $>0.999$ \\
\hline Chronic steroid use & $5(1.4)$ & $0(0)$ & 0.99 & $0.98-1.00$ & $>0.999$ \\
\hline Previous cardiac surgery & $5(1.4)$ & $0(0)$ & 0.99 & $0.98-1.00$ & $>0.999$ \\
\hline Previous abdominal surgery & $40(10.9)$ & $0(0)$ & 7.20 & $2.72-19.09$ & $>0.999$ \\
\hline Therapeutic anticoagulation & $16(4.3)$ & $2(12.5)$ & 1.14 & $0.94-1.37$ & $0.010^{*}$ \\
\hline Abnormal serum albumin $<3.5 \mathrm{~g} / \mathrm{dL}$ & $46(16.4)$ & $3(6.5)$ & 1.07 & $0.99-1.15$ & $0.015^{*}$ \\
\hline Anemia (abnormal hematocrit $<36 \%$ ) & $24(7.3)$ & $0(0)$ & 0.99 & $0.98-1.00$ & $>0.999$ \\
\hline
\end{tabular}

ASA PS, American Society of Anesthesiologists physical status.

${ }^{a}$ The percentage of the patient with severe complication among the risk cohort. ${ }^{*} \mathrm{P}<0.05$, significant difference.

Table 7. Multivariate analysis by the binary logistic regression for severe complication of laparoscopic sleeve gastrectomy

\begin{tabular}{lrcc}
\hline \multicolumn{1}{c}{ Variable } & Odds ratio & 95\% Confidence interval & P-value \\
\hline Male sex & 3.59 & 0 & 0.993 \\
Body mass index $\geq 60 \mathrm{~kg} / \mathrm{m}^{2}$ & 11.31 & $0.18-701.91$ & 0.250 \\
Smoker within the last year & 13.74 & $0.44-427.94$ & 0.135 \\
ASA PS classification $\geq$ III & $6,184,415.93$ & 0 & 0.996 \\
Deep vein thrombosis & 1.13 & 0.994 \\
Therapeutic anticoagulation & 0.00 & $0.01-55.67$ & 0.995 \\
Abnormal serum albumin $<3.5 \mathrm{~g} / \mathrm{dL}$ & 0.79 & 0.912
\end{tabular}

ASA PS, American Society of Anesthesiologists physical status.

according to the critical risk factors. With regard to the type of procedure, Hutter et al. [29] reported that laparoscopic SG has higher rates of organ space infection, renal insufficiency, and sepsis but lower rates of ventilator dependence when compared to laparoscopic RYGB. In addition, operative time, conversion and age were reported as risk factors for leak in laparoscopic SG [30]. In our study, preoperative hypoalbuminemia had significant associations with occurrence of deep surgical site infection and leak. Open approach had significant associations with occurrence of superficial surgical site infection, deep surgical site infection, and respiratory complication. However, hypertension, male sex and type of bariatric procedure had no relationship with occurrence of the specific type of complication. Except in cases of revision or open surgery, previous abdominal surgery had significant associations with occurrence of deep surgical site infection and leak after laparoscopic RYGB. However, in cases of laparoscopic primary SG, none of the risk factors had statistical associations with the occurrence of any specific type of complication. More research needs to be done to better understand the relationship between 
Table 8. Risk factors for severe complication of laparoscopic Roux-en-Y gastric bypass

\begin{tabular}{|c|c|c|c|c|c|}
\hline Variable & $\begin{array}{c}\text { No. of } \\
\text { patients (\%) }\end{array}$ & $\begin{array}{c}\text { No. of } \\
\text { complications }(\%)^{\text {a) }}\end{array}$ & $\begin{array}{l}\text { Odds } \\
\text { ratio }\end{array}$ & $\begin{array}{c}\text { 95\% Confidence } \\
\text { interval }\end{array}$ & P-value \\
\hline Age $\geq 50 \mathrm{yr}$ & $161(46.3)$ & $2(1.2)$ & 1.01 & $0.99-1.03$ & 0.598 \\
\hline Male sex & $67(19.3)$ & $1(1.5)$ & 1.01 & $0.98-1.04$ & 0.476 \\
\hline Body mass index $\geq 60 \mathrm{~kg} / \mathrm{m}^{2}$ & $24(6.5)$ & $0(0)$ & 0.98 & $0.97-1.00$ & $>0.999$ \\
\hline Open conversion & $12(3.3)$ & $0(0)$ & 0.98 & $0.97-1.00$ & $>0.999$ \\
\hline Long operative time $>120 \mathrm{~min}$ & $58(15.8)$ & $0(0)$ & 0.98 & $0.97-1.00$ & 0.595 \\
\hline Smoker within the last year & $49(13.3)$ & $3(6.1)$ & 1.06 & $0.98-1.13$ & $0.033^{*}$ \\
\hline Functional status: partial dependence & $4(1.1)$ & $0(0)$ & 0.98 & $0.97-1.00$ & $>0.999$ \\
\hline ASA PS classification $\geq$ III & $240(66.3)$ & $5(2.1)$ & 1.01 & $0.99-1.04$ & 0.668 \\
\hline Prophylactic antibiotics use & $279(98.2)$ & $4(1.4)$ & 1.02 & $1.00-1.03$ & $>0.999$ \\
\hline Diabetes & $173(47.0)$ & $0(0)$ & 0.97 & $0.95-0.99$ & $>0.999$ \\
\hline Chronic obstructive lung disease & $19(5.2)$ & $2(10.5)$ & 1.11 & $0.95-1.29$ & $0.034^{*}$ \\
\hline Pulmonary thromboembolism & $4(1.1)$ & $0(0)$ & 0.97 & $0.89-1.41$ & $>0.999$ \\
\hline Obstructive sleep apnea & $272(73.9)$ & $4(1.5)$ & 0.99 & $0.96-1.03$ & 0.653 \\
\hline Gastroesophageal reflux disease & $168(45.7)$ & $3(1.8)$ & 1.00 & $0.98-1.03$ & $>0.999$ \\
\hline Myocardial ischemia & $13(3.5)$ & $0(0)$ & 0.98 & $0.97-1.00$ & $>0.999$ \\
\hline Hyperlipidemia & $183(49.7)$ & $0(0)$ & 0.97 & $0.94-0.99$ & $>0.999$ \\
\hline Hypertension & $241(65.5)$ & $4 / 241(1.7)$ & 1.00 & $0.97-1.03$ & $>0.999$ \\
\hline Deep vein thrombosis & $15(4.1)$ & $0(0)$ & 0.98 & $0.97-1.00$ & $>0.999$ \\
\hline Renal insufficiency & $2(0.5)$ & $0(0)$ & 0.99 & $0.97-1.00$ & $>0.999$ \\
\hline Chronic steroid use & $3(0.8)$ & $0(0)$ & 0.98 & $0.97-1.00$ & $>0.999$ \\
\hline Previous cardiac surgery & $8(2.2)$ & $0(0)$ & 0.98 & $0.97-1.00$ & $>0.999$ \\
\hline Previous abdominal surgery & $48(13.0)$ & $4(8.3)$ & 1.08 & $1.00-1.18$ & $0.003 *$ \\
\hline Therapeutic anticoagulation & $9(2.4)$ & $0(0)$ & 0.98 & $0.97-1.00$ & $>0.999$ \\
\hline Abnormal serum albumin $<3.5 \mathrm{~g} / \mathrm{dL}$ & $40(12.7)$ & $4(10.0)$ & 1.10 & $1.00-1.23$ & $0.001 *$ \\
\hline Anemia (abnormal hematocrit $<36 \%$ ) & $49(13.8)$ & $3(6.1)$ & 1.06 & $0.98-1.13$ & $0.037^{*}$ \\
\hline
\end{tabular}

ASA PS, American Society of Anesthesiologists physical status.

a) The percentage of the patient with severe complication among the risk cohort. $* \mathrm{P}<0.05$, significant difference.

Table 9. Multivariate analysis by the binary logistic regression for severe complication of laparoscopic Roux-en-Y gastric bypass

\begin{tabular}{lccc}
\hline \multicolumn{1}{c}{ Variable } & Odds ratio & 95\% Confidence interval & P-value \\
\hline Smoker within the last year & 2.98 & $0.23-38.11$ & 0.401 \\
Chronic obstructive lung disease & 12.15 & $0.37-404.32$ & 0.163 \\
Previous abdominal surgery & 43.63 & $2.09-913.00$ & $0.015^{*}$ \\
Abnormal serum albumin $<3.5 \mathrm{~g} / \mathrm{dL}$ & 15.61 & $0.84-290.04$ & 0.065 \\
Anemia (abnormal hematocrit $<36 \%)$ & 3.12 & $0.25-38.55$ & 0.376 \\
\hline
\end{tabular}

$* \mathrm{P}<0.05$, significant difference.

type of complication and risk factors.

There has been a worldwide shift in procedure selection toward SG for reasons of superior simplicity [1]. In this institution, there were steadily increasing numbers of patients undergoing SG from 2010 to 2015. Nevertheless, it seems difficult to form solid conclusions about the superiority of SG or RYGB in efficacy and feasibility due to confounding conclusions from previous publications [4-9]. Many studies report better safety profiles in SG than in RYGB $[4,5,19,20]$. Trastulli et al. [20] reported that complication rates of laparoscopic RYGB (20.9\%) were higher than that of laparoscopic SG (12.9\%) through a systematic review of randomized controlled trials over a 5-year period. In addition, Leyba et al. [19] also reported that laparoscopic RYGB (21.2\%) had a higher incidence of major complications than laparoscopic SG (11.1\%). Furthermore, Lorente et al. [21] reported that the probability of suffering complications after laparoscopic RYGB is five times higher than after laparoscopic SG (OR, 5.63; 95\% confidence interval, 1.5213.51) $(\mathrm{P}=0.007)$.

On the other hand, relatively recent articles have demonstrated similar, or even fewer incidence of reoperation, readmission and mortality in RYGB, when compared to SG [7- 


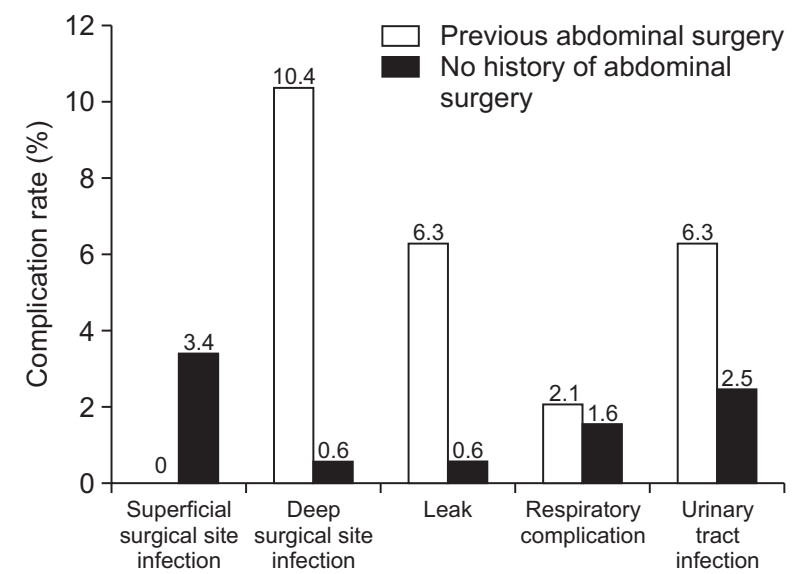

Fig. 3. Relationship between previsous abdominal surgery and type of complication after laparoscopic Roux-en-Y gastric bypass.

9,18]. Melissas et al. [9] reported that an early postoperative complication rate of $3.02 \%$ for RYGB was significantly higher than $2.12 \%$ seen after SG $(\mathrm{P}<0.001)$, but both procedures were performed with very low complication and reoperation rates. In addition, the SG group had significantly higher reoperation rates $(75.72 \%)$ from the readmitted patients than that of the RYGB group (50.5\%). Moreover, Goitein et al. [16] demonstrated that no significant difference was found between the groups regarding overall and complication grade-specific rates. Early complications occurred in $3.7 \%$ and $4.3 \%$ of patients following laparoscopic SG and laparoscopic RYGB, respectively $(P=0.9)$. In addition, Peterli et al. [5] reported, through a randomized controlled trial, that there was no statistically significant difference in 30-day complication between laparoscopic RYGB (17.2\%) and laparoscopic SG (8.4\%) $(\mathrm{P}=0.067)$ as well as severe complication $(\mathrm{P}=0.21)$. Furthermore, after a 3-year followup, the same authors reported that there was no statistically significant difference of 1-month to 3-year complications between laparoscopic RYGB (15\%) and laparoscopic SG (8\%) (P
$=0.15)$ as well as reoperation rate $(P=0.15)$ and long-term complication such as vitamin deficiencies $(P=0.59)$ [18]. In this study, laparoscopic primary RYGB complication rate $(9.5 \%)$ was higher than that of laparoscopic primary SG (3.5\%). However, there was no significant difference in incidence of severe complications between the groups $(1.1 \%$ for both, $\mathrm{P}=0.752)$ (Table 6).

There are several limitations to this study. First of all, it is a retrospective study. Therefore, a prospective randomization of patients to either SG or RYGB might have yielded different respective complication rates or different conclusions about risk factors. Also, there was some missing data about gender in the course of data processing. Second, only 30-day complication and mortality were included in this study. Although most severe complications happen within the first 30 days postoperatively, that can result in underestimation of real risk. Third, the patients who had revisional operation were included. Exclusion of revision cases did cause different conclusions about the risk of the 2 operations. Fourth, significant risk factors were not well identified according to separate groups based on surgical procedure or approach. The size of the study group may limit the detection of clinically important factors. Nevertheless, this study has several advantages such as the use of more recent data - since 2010, the use of universally accepted ClavienDindo classification and, in particular, analysis of types of complication according to significant risk factors.

In conclusion, recognition and optimization of these risk factors, particularly male sex, open surgery, hypertension, serum albumin, and previous abdominal surgery, may predict operative risk preoperatively and improve outcomes.

\section{CONFLICTS OF INTEREST}

No potential conflict of interest relevant to this article was reported.

\section{REFERENCES}

1. Reames BN, Finks JF, Bacal D, Carlin AM, Dimick JB. Changes in bariatric surgery procedure use in Michigan, 2006-2013. JAMA 2014:312:959-61.

2. Schauer PR, Kashyap SR, Wolski K, Brethauer SA, Kirwan JP, Pothier CE, et al. Bariatric surgery versus intensive medical therapy in obese patients with diabetes. N Engl J Med 2012;366:1567-76.
3. Chang SH, Stoll CR, Song J, Varela JE, Eagon CJ, Colditz GA. The effectiveness and risks of bariatric surgery: an updated systematic review and meta-analysis, 2003-2012. JAMA Surg 2014;149:275-87.

4. Zhang Y, Wang J, Sun X, Cao Z, Xu X, Liu $D$, et al. Laparoscopic sleeve gastrectomy versus laparoscopic Roux-en-Y gastric bypass for morbid obesity and related comorbidities: a meta-analysis of 21 studies. Obes Surg 2015;25:19-26.

5. Peterli R, Borbély Y, Kern B, Gass M, Peters T, Thurnheer M, et al. Early results of the Swiss Multicentre Bypass or Sleeve Study (SM-BOSS): a prospective randomized trial comparing laparoscopic sleeve gastrectomy and Roux-en-Y gastric bypass. Ann Surg 2013;258:690-4. 
6. Szczuko M, Komorniak N, Hoffmann M, Walczak J, Jaroszek A, Kowalewski B, et al. Body weight reduction and biochemical parameters of the patients after RYGB and SG bariatric procedures in 12-month observation. Obes Surg 2017;27:940-7.

7. Wang MC, Guo XH, Zhang YW, Zhang YL, Zhang HH, Zhang YC. Laparoscopic Roux-en-Y gastric bypass versus sleeve gastrectomy for obese patients with Type 2 diabetes: a meta-analysis of randomized controlled trials. Am Surg 2015;81:166-71.

8. Zellmer JD, Mathiason MA, Kallies KJ, Kothari SN. Is laparoscopic sleeve gastrectomy a lower risk bariatric procedure compared with laparoscopic Roux-en-Y gastric bypass? A meta-analysis. Am J Surg 2014:208:903-10.

9. Melissas J, Stavroulakis K, Tzikoulis V, Peristeri A, Papadakis JA, Pazouki A, et al. Sleeve gastrectomy vs Roux-en-Y gastric bypass. Data from IFSO-European Chapter Center of Excellence Program. Obes Surg 2017;27:847-55.

10. DeMaria EJ, Murr M, Byrne TK, Blackstone R, Grant JP, Budak A, et al. Validation of the obesity surgery mortality risk score in a multicenter study proves it stratifies mortality risk in patients undergoing gastric bypass for morbid obesity. Ann Surg 2007;246:578-82.

11. Longitudinal Assessment of Bariatric Surgery (LABS) Consortium, Flum DR, Belle SH, King WC, Wahed AS, Berk P, et al. Perioperative safety in the longitudinal assessment of bariatric surgery. $\mathrm{N}$ Engl J Med 2009:361:445-54.

12. Coblijn UK, Lagarde SM, de Raaff CA, de Castro SM, van Tets WF, Jaap Bonjer H, et al. Evaluation of the obesity surgery mortality risk score for the prediction of postoperative complications after primary and revisional laparoscopic Roux-en-Y gastric bypass. Surg Obes Relat Dis 2016; 12:1504-12.

13. Aminian A, Brethauer SA, Sharafkhah M, Schauer PR. Development of a sleeve gastrectomy risk calculator. Surg Obes Relat Dis 2015;11:758-64.

14. Gupta PK, Franck C, Miller WJ, Gupta H,
Forse RA. Development and validation of a bariatric surgery morbidity risk calculator using the prospective, multicenter NSQIP dataset. J Am Coll Surg 2011;212:301-9.

15. Kolbe N, Carlin AM, Bakey S, Louwers L, Horst HM, Rubinfeld I. Assessing risk of critical care complications and mortality in the elective bariatric surgery population using a modified frailty index. Obes Surg 2015;25:1401-7.

16. Goitein D, Raziel A, Szold A, Sakran N. Assessment of perioperative complications following primary bariatric surgery according to the Clavien-Dindo classification: comparison of sleeve gastrectomy and Roux-Y gastric bypass. Surg Endosc 2016:30:273-8.

17. Dindo D, Demartines N, Clavien PA. Classification of surgical complications: a new proposal with evaluation in a cohort of 6336 patients and results of a survey. Ann Surg 2004:240:205-13.

18. Peterli R, Wölnerhanssen BK, Vetter D, Nett P, Gass M, Borbély Y, et al. Laparoscopic sleeve gastrectomy versus Roux-YGastric bypass for morbid obesity-3-year outcomes of the prospective randomized swiss multicenter bypass or sleeve study (SM-BOSS). Ann Surg 2017; 265:466-73.

19. Leyba JL, Llopis SN, Aulestia SN. Laparoscopic Roux-en-Y gastric bypass versus laparoscopic sleeve gastrectomy for the treatment of morbid obesity. a prospective study with 5 years of followup. Obes Surg 2014:24:2094-8.

20. Trastulli S, Desiderio J, Guarino S, Cirocchi R, Scalercio V, Noya G, et al. Laparoscopic sleeve gastrectomy compared with other bariatric surgical procedures: a systematic review of randomized trials. Surg Obes Relat Dis 2013;9:816-29.

21. Lorente L, Ramón JM, Vidal P, Goday A, Parri A, Lanzarini E, et al. Obesity surgery mortality risk score for the prediction of complications after laparoscopic bariatric surgery. Cir Esp 2014:92:316-23.

22. Turner PL, Saager L, Dalton J, Abd-Elsayed A, Roberman D, Melara P, et al. A nomogram for predicting surgical complications in bariatric surgery patients. Obes Surg 2011;21:655-62.

23. Livingston EH. Development of bariatric surgery-specific risk assessment tool. Surg Obes Relat Dis 2007;3:14-20.

24. Dayer-Jankechova A, Fournier P, Allemann P, Suter M. Complications after laparoscopic Roux-en-Y gastric bypass in 1573 consecutive patients: are there predictors? Obes Surg 2016;26:12-20.

25. Hutter MM, Randall S, Khuri SF, Henderson WG, Abbott WM, Warshaw AL. Laparoscopic versus open gastric bypass for morbid obesity: a multicenter, prospective, risk-adjusted analysis from the National Surgical Quality Improvement Program. Ann Surg 2006; 243:65762.

26. Campos GM, Ciovica R, Rogers SJ, Posselt AM, Vittinghoff E, Takata M, et al. Spectrum and risk factors of complications after gastric bypass. Arch Surg 2007;142: 969-75.

27. Sekhar N, Torquati A, Youssef Y, Wright JK, Richards WO. A comparison of 399 open and 568 laparoscopic gastric bypasses performed during a 4-year period. Surg Endosc 2007;21:665-8.

28. Aminian A, Andalib A, Khorgami Z, Kashyap SR, Burguera B, Schauer PR, et al. A nationwide safety analysis of bariatric surgery in nonseverely obese patients with type 2 diabetes. Surg Obes Relat Dis 2016;12:1163-70.

29. Hutter MM, Schirmer BD, Jones DB, Ko CY, Cohen ME, Merkow RP, et al. First report from the American College of Surgeons Bariatric Surgery Center Network: laparoscopic sleeve gastrectomy has morbidity and effectiveness positioned between the band and the bypass. Ann Surg 2011;254:410-20.

30. Benedix F, Poranzke O, Adolf D, Wolff S, Lippert H, Arend J, et al. Staple line leak after primary sleeve gastrectomyrisk factors and mid-term results: do patients still benefit from the weight loss procedure? Obes Surg 2017;27:1780-8. 